\title{
Sistem Informasi Jasa Pemesanan Percetakan Berbasis Android
}

\author{
Zulkarnain Purnomo \\ Prodi Sistem Informasi \\ STIMIK Ichsan Gorontalo \\ Gorontalo, Indonesia \\ zulkarnainpurnomo18@gmail.com
}

\author{
Jorry Karim \\ Prodi Sistem Informasi \\ STIMIK Ichsan Gorontalo \\ Gorontalo, Indonesia \\ oyie.potlot@gmail.com
}

\author{
Bahtiar Senung \\ Prodi Sistem Informasi \\ STIMIK Ichsan Gorontalo \\ Gorontalo, Indonesia \\ bahtiarsenung@gmail.com
}

\author{
Syahrir Abdussamad \\ Prodi Teknik Elektro \\ Universitas Negeri Gorontalo \\ Gorontalo, Indonesia \\ syahrirabdussamad@ung.ac.id
}

\section{Diterima : Juni 2020 \\ Disetujui : Juli 2020 \\ Dipublikasi : Juli 2020}

Abstrak-Percetakan Mufidah Digital Printing setiap bulannya melayani order pencetakan, yang menjadi permasalahan selama ini adalah proses pelayanan kepada pelanggan yang akan melakukan order jasa percetakan tidak dapat terlayani dengan cepat hal ini karena banyaknya pelanggan serta ruang yang tersedia tidak terlalu luas dan pelanggan harus mendatangi Percetakan Mufidah Digital Printing untuk melakukan order pencetakan. Tujuan dari artikel ini untuk merancang sistem informasi jasa pemesanan percetakan berbasis android pada Percetakan Mufida Digital Printing Kota Gorontalo untuk memudahkan pelanggan melakukan pemesanan percetakan. Dalam merancang aplikasi ini menggunakan bahasa UML (Unified Modelling Language) dan diimplementasikan dengan menggunakan Android Studio, PHP dan MySQL. Metode yang digunakan adalah penelitian deskriptif yang berusaha menggambarkan dan menginterpretasi objek sesuai dengan apa adanya, di dalamnya terdapat upaya mendeskripsikan, mencatat, analisa, dan menginterprestasikan kondisi-kondisi yang saat ini terjadi atau ada. Berdasarkan hasil pengujian dengan menggunakan test case membuktikan bahwa sistem informasi jasa pemesanan percetakan berbasis android pada mufida digital printing ini lebih efektif dan efisien dibandingkan secara manual. Hasil pengujian: $\mathrm{V}(\mathrm{G}) \quad=20-17+2=5$, $\mathrm{V}(\mathrm{G})=4+1=5$, Cyclomatic Complexity $(\mathrm{CC})=\mathrm{R} 1, \mathrm{R2}$, $\mathbf{R 3 , R 4 , R 5 =}$ 5. Diperoleh kesimpulan bahwa desain system informasi jasa pemesanan percetakan berbasis android dapat memudahkan konsumen untuk melakukan order percetakan dengan kelebihan fitur tambahan berupa notifikasi untuk pelanggan sehingga mempermudah proses produksi dari order cetakan yang dilakukan.

Kata Kunci : Sistem Informasi, Mufida , android, php, mysql

Abstract-Printing of Mufidah Digital Printing every month serving printing orders, which has been a concern so far is the process of service to customers who will order printing services cannot be served quickly because this Mufidah Digital Printing customers make printing orders. The purpose of this article is to open an android-based printing order ordering information system in Gorontalo City Mufida Digital Printing Printing to provide printing ordering services. In completing this application using the UML (Unified Modeling Language) language and implemented using Android Studio, PHP and MySQL. The method used is descriptive research that discusses and interprets objects that are in accordance with what exists, where there are those that involve describing, loading, analyzing, and interpreting the conditions that currently occur or exist. Based on the test results using a test case prove that the Android-based ordering information system on digital printing mufida is more effective and efficient using manuals. Test results: $V(G)=20-17$ $+2=5, V(G)=4+1=5$, Cyclone Complexity $(C C)=R 1, R 2$, $R 3, R 4, R 5=5$. Obtained by the information system design Android-based printing order orders can make it easier for customers to order printing by loading additional notification features for customers to make the production process from ordering prints.

Keywords: Information Systems, Mufida, android, php, mysql

\section{Pendahuluan}

Era globalisasi saat ini mengharuskan pelayanan terhadap jasa percetakan harus dilakukan dengan menyediakan sistem informasi sebagai syarat untuk meningkatkan mutu pelayanan.

Sistem informasi ini dikembangkan dengan memanfaatkan aplikasi yang bisa digunakan baik untuk android maupun yang berbasis web.

Percetakan Mufidah Digital Printing [1], merupakan salah satu usaha percetakan terbesar di Kota Gorontalo, yang melayani kebutuhan percetakan baik berupa baliho, buku, kalender, kop surat, brosur, undangan dan semua hasil cetakan. Saat ini yang menjadi pelanggan adalah sekolah, perguruan tinggi, perkantoran, dunia usaha, dunia industri dan masyarakat umum.

Percetakan Mufidah Digital Printing setiap bulannya melayani order pencetakan. Dalam proses pelaksanaannya mengalami permasalahan terutama dalam proses pelayanan kepada pelanggan yang akan melakukan order jasa percetakan dimana tidak dapat terlayani dengan cepat hal ini karena banyaknya pelanggan serta ruang yang tersedia tidak terlalu luas dan juga pelanggan harus mendatangi Percetakan Mufidah Digital Printing untuk melakukan order pencetakan.

Artikel ini bertujuan untuk merancang sistem informasi jasa pemesanan percetakan berbasis android, oleh karena permasalahan diatas maka perlu dibuatkan sebuah sistem informasi jasa pemesanan percetakan berbasis android dan 
web agar supaya memudahkan proses order percetakan, sehingga proses pengerjaan dapat dilakukan lebih cepat dan memudahkan pelanggan tanpa perlu datang ke Percetakan Mufidah Digital Printing.

Artikel ini dibuat tidak terlepas dari hasil-hasil penelitian terdahulu yang pernah dilakukan sebagai bahan referensi, yang tidak terlepas dari topik artikel ini yakni sebagai berikut :

Hasil penelitian dari Rahmat Hidayat [2], Program Studi Sistem Informasi, STMIK Nusa Mandiri Jakarta dengan judul penelitian sistem informasi pemesanan jasa cetak berbasis web pada CV. Vida Plus Jakarta. Kesimpulan dari hasil penelitian ini adalah dengan dibuatnya website usaha untuk CV. Vida Plus diharapkan akan memudahkan dalam melakukan proses pemesanan produk percetakan yang dilakukan oleh pelanggan. Dengan adanya website CV. Vida Plus akan memudahkan proses pemasaran produkproduk yang ditawarkan kepada pelanggan lama ataupun pelanggan baru dengan tidak dibatasi oleh ruang dan waktu.

Hasil penelitian dari Wahyu Priadi dan Nurgiyatna, M.Sc, Ph.D [3], dalam naskah publikasi program studi Tehnik Informatika Fakultas Komunikasi dan Informatika Universitas Muhammadiyah Surakarta dengan judul penelitian Perancangan Sistem Informasi Penjualan Kerajinan Rotan Berbasis Android (Studi Kasus di Klaster Rotan Trangsan, Gatak, Sukoharjo). Kesimpulan dari hasil penelitian ini adalah Berdasarkan perancangan dan pembuatan aplikasi sistem informasi penjualan kerajinan rotan berbasis android telah selesai dibuat dan telah dilakukan pengujian dengan mengambil sample sebanyak 12 orang yang terdiri dari 2 penjual dan 10 pembeli. Aplikasi penjualan kerajinan rotan berbasis android sebagai sarana informasi dan jual - beli dan mempermudah pengguna untuk memperoleh informasi. Aplikasi penjualan ini praktis dan efisien. Berdasarkan hal tersebut dapat disimpulkan bahwa tujuan dari perancangan sistem informasi penjualan kerajinan rotan berbasis android, dengan tujuan memberikan informasi dan mempermudah transaksi jual - beli telah tercapai

Penelitian yang dilakukan oleh Eka Nugraha Sari dengan judul Aplikasi Informasi Dan Pemesanan Tiket Travel Berbasis Android [4], Pemanfaatan Arduino telah banyak dilakukan, diantaranya pada aplikasi sistem peringatan dini [5, 6] dan jam digital penentu waktu sholat [7]. Hasil dari penelitian ini yaitu pada saat pemesanan tiket masih menggunakan cara konvensional yaitu pelanggan datang ke tempat pemberangkatan untuk memesan tiket dan kemudian baru dapat menanyakan jam keberangkatan dan fasilitas yang terdapat di dalamnya. Cara ini kurang efektif dan menghabiskan waktu dari calon pelanggan

Dari beberapa penelitian sebagai sumber rujukan dapat disimpulkan bahwa perbedaan dari ketiga penelitian dengan artikel yang dibuat yakni dari lokasi penelitian dan penambahan notifkasi. Untuk artikel ini terdapat fitur tambahan yaitu notifikasi sehingga lebih mudah pelanggan memantau proses produksi dari order cetakan yang dilakukan.

\section{METODE}

Metode yang digunakan dalam artikel ini adalah metode penelitian deskriptif, merupakan metode penelitian yang berusaha menggambarkan dan menginterpretasi objek sesuai dengan apa adanya, di dalamnya terdapat upaya mendeskripsikan, mencatat, analisa, dan menginterprestasikan kondisi-kondisi yang saat ini terjadi atau ada.

Adapun tahapan dalam yang harus dilakukan dalam artikel ini adalah mengenal objek penelitian, tahap analisis, tahap desain, tahap pengujian dan tahap implementasi.

\section{A. Tahap Analisis}

Kegiatan yang dilakukan pada tahapan pengembangan sistem yang melingkupi hal identifikasi masalah berupa pelayanan tidak dapat dilakukan dengan cepat dan customer harus mendatangi Percetakan Mufidah Digital Printing untuk melakukan order pencetakan.

\section{Jenis dan Sumber Data}

Data primer dalam penelitian ini yaitu segala data yang ditemui pada saat observasi di kantor Mufidah Digital Printing Gorontalo; Data sekunder; data yang diperoleh secara tidak langsung bersumber dari dokumentasi, literatur, buku, jurnal, dan informasi lainnya yang ada hubungannya dengan masalah yang diteliti.

\section{Metode Pengumpulan Data}

Teknik pengumpulan data dilakukan dengan cara: Observasi, teknik ini dilakukan dengan melakukan pengamatan berlangsung di tempat penelitian, yaitu pada kantor Mufidah Digital Printing Gorontalo; wawancara, pengumpulan data dengan cara tatap muka dan tanya jawab langsung dengan sumber data, yaitu pimpinan Mufidah Digital Printing Gorontalo.

\section{Analisa Sistem Yang Berjalan}

Aktor pada sistem yang berjalanyaitu customer, bagian pelayanan, bagian produksi dan kasir. Pada sistem yang berjalan customer dapat melakukan order, aktor bagian layanan menerima order dari customer, selanjutnya aktor bagian produksi melakukan produksi cetak, dan aktor kasir menerima pembayaran customer dan menyerahkan hasil cetakan.

\section{Analisa Sistem yang Diusulkan}

Dari sistem yang berjalan di atas sebenarnya tidak terlalu berbeda dengan sistem yang diusulkan. Aktor pada sistem yang diusulkan masih tetap sama dengan sistem yang sedang berjalan. Akan tetapi pada sistem yang diusulkan berusaha untuk mengatasi permasalahan yang ditemui pada sistem yang sedang berjalan khususnya untuk memudahkan customer melakukan order percetakan.

\section{B. Tahap Desain}

Adapun tahap pertama dari desain sistem yaitu arsitektur dan pemodelan aplikasi, dimana pada tahap ini kita melakukan pertimbangan-pertimbangan mengenai bagaimana suatu sistem akan diterapkan, baik dalam teknologi dan lingkungan implementasi. Pada tahap ini digunakan Unified Modelling Language (UML), dimana kita memodelkan persyaratan bisnis logis dari suatu sistem informasi.

Selanjutnya dilakukan tahap desain database, dimana semua proses membuat, membaca, memperbaharui, dan menghapus (create, read, update, delete) data. Data 
disimpan dalam file dan database. Termasuk dalam tahap ini adalah pemodelan field kunci, record table, relasi database, entitas data. Kemudian masuk pada tahap desain dan prototyping input dan output serta antar muka sistem, menggambarkan masukan dan keluaran bagi pengguna sistem, baik dalam bentuk formulir masukan, sistem organisasi menu, bentuk cetakan kertas ataupun tampilan ke layar monitor. Implementasi input merupakan masukan input dari keyboard dan mouse, penyesuaian tipe pengguna sistem, penggunaan gambar dan simbol (icon).

\section{Tahap Pengujian}

Melakukan pengetesan terhadap sistem yang telah selesai dibuat sebelum diimplementasikan dengan menggunakan teknik pengujian perangkat lunak yang telah ada yakni menggunakan pengujian White Box dan Black Box Testing.

\section{Tahap Implementasi}

Tahap implementasi sistem (System Implementasi) merupakan tahap meletakkan sistem supaya siap dioperasikan. Dalam tahap ini, penerapan pada Mufidah Digital Printing Gorontalo.

\section{HASIL DAN PEMBAHASAN}

\section{A. Hasil}

Setelah perancangan sistem informasi jasa pemesanan percetakan di buat, maka yang dilakukan selanjutnya adalah:

\section{Analisis Sistem}

Usecase diagram digunakan untuk menggambarkan peran setiap aktor terhadap sistem berjalan atau sistem yang diusulkan. Usecase sistem yang sedang berjalan dan sistem yang direncanakan.

\section{Sistem Yang Berjalan}

Penyebab permasalahan yakni proses pelayanan tidak dapat dilakukan dengan cepat dan pelanggan harus mendatangi Percetakan Mufidah Digital Printing untuk melakukan order pencetakan.

\section{Sistem yang Direncanakan}

Hasil analisis sistem yang sedang berjalan dalam artikel ini menemukan beberapa faktor yang menyebabkan permasalahan tersebut terjadi seperti pelanggan harus datang mengecek langsung ke percetakan mufidah digital printing. Oleh karena itu dengan menggunakan metode yang dipilih peneliti mengusulkan rancangan sistem untuk mengatasi permasalahan yang terjadi yakni sistem yang sedang direncanakan. Aktor bagian pelayanan harus melakukan login terlebih dahulu untuk mengakses menu admin. Menu admin yang di sediakan adalah pendataan kategori, digunakan untuk menginput kategori produk percetakan. Menu setting harga merupakan menu untuk melakukan pendataan harga berdasarkan kategori. Menu data pelanggan digunakan untuk melakukan pengecekan data pelanggan. Menu data order digunakan untuk melakukan proses terhadap order dari pelanggan. Menu data produksi digunakan untuk melakukan pendataan terhadap produksi percetakan berdasarkan order pelanggan. Menu pengambilan order digunakan untuk melakukan pendataan terhadap pengambilan order percetakan oleh pelanggan.

Pelanggan dapat mengakses menu berupa menu order cetak, digunakan untuk menampilkan form pengisian data order cetak. Menu daftar order digunakan untuk melihat daftar order yang telah dilakukan serta melihat jumlah yang harus dibayar, dan melihat kondisi order. Menu cek harga cetak digunakan untuk melihat harga per item kategori cetak. Menu Informasi digunakan untuk melihat informasi cara order cetak, cara pembayaran dan profil perusahaan. Menu About aplikasi digunakan untuk menampilkan data tentang aplikasi. Menu logout digunakan untuk keluar dari user aktif.

\section{B. Desain Input Secara Umum}

Desain input pada sistem informasi jasa pemesanan percetakan baliho berbasis android terbagi atas 2 (dua) yaitu dari sisi web dan dari sisi android. Hirarki kata sebagai berikut:

1. Desain input dengan Web

a. Desain Tampilan Login User

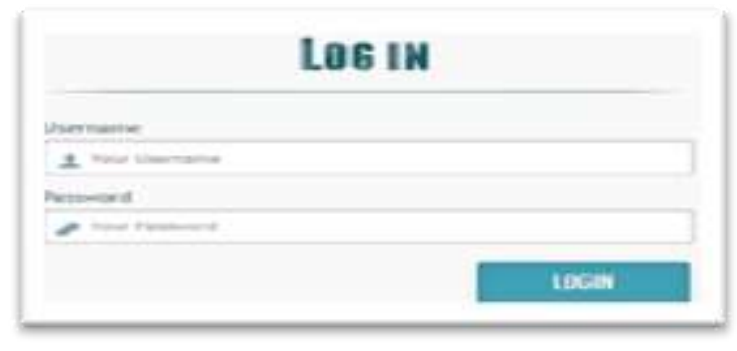

Gambar 1. Desain Input Login User

Tampilan form seperti Gambar 1, digunakan oleh admin untuk masuk ke dalam sistem. Untuk masuk ke dalam sistem admin harus menginputkan user name dan password. Jika password yang diinputkan benar maka secara otomatis halaman akan berpindah ke beranda, jika salah maka halaman akan menampilkan pesan salah.

\section{b. Form Input Data Kategori Cetak}

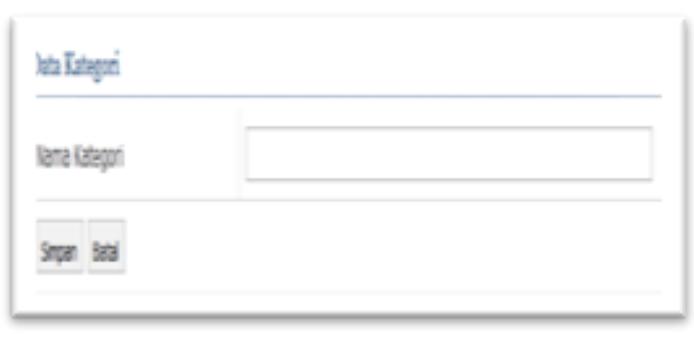

Gambar 2. Desain Input Data Kategori Cetak

Tampilan form untuk Gambar 2, digunakan oleh admin untuk mengisi data kategori cetak, data yang diinput adalah nama kategori. 


\section{c. Form Input Data Setting Harga}

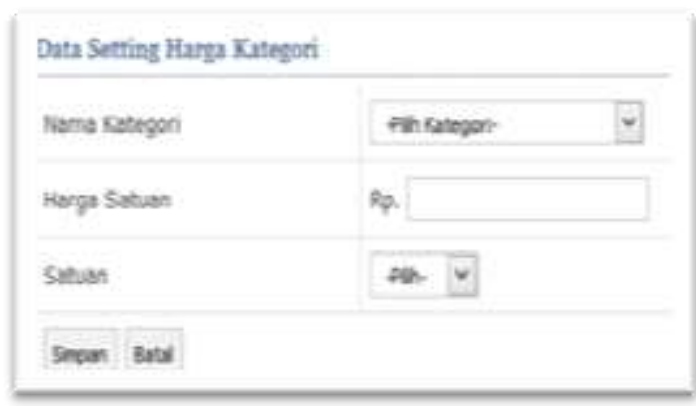

Gambar 3. Desain input data setting harga

Tampilan form seperti Gambar 3, digunakan oleh admin untuk mengisi data setting harga cetak, data yang di input adalah pilihan kategori, harga satuan, dan satuan.

\section{d. Form Data Order}

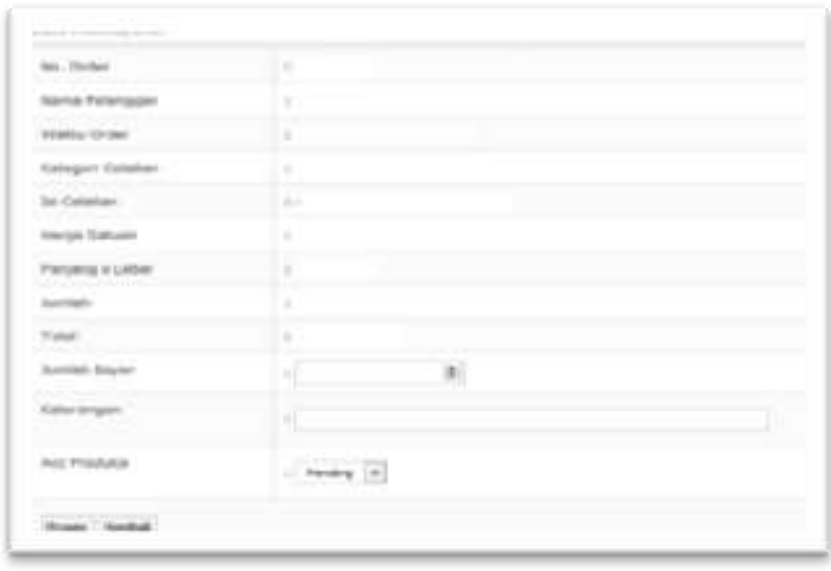

Gambar 4. Desain Data Order

Tampilan form Gambar 4 digunakan oleh admin untuk menampilkan data order, data yang diinput adalah jumlah bayar, keterangan, dan acc produksi.

\section{e. Form Data Produksi}

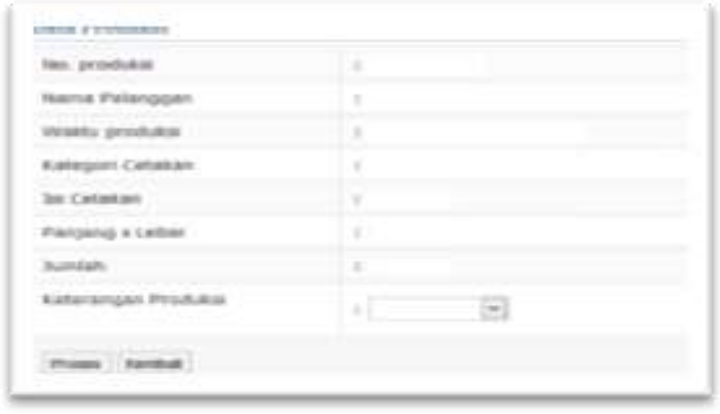

Gambar 5. Desain Data Produksi

Tampilan form Gambar 5, digunakan oleh admin untuk menampilkan data produksi, data yang diinput adalah keterangan produksi.

\section{f. Form Data Pengambilan Order}

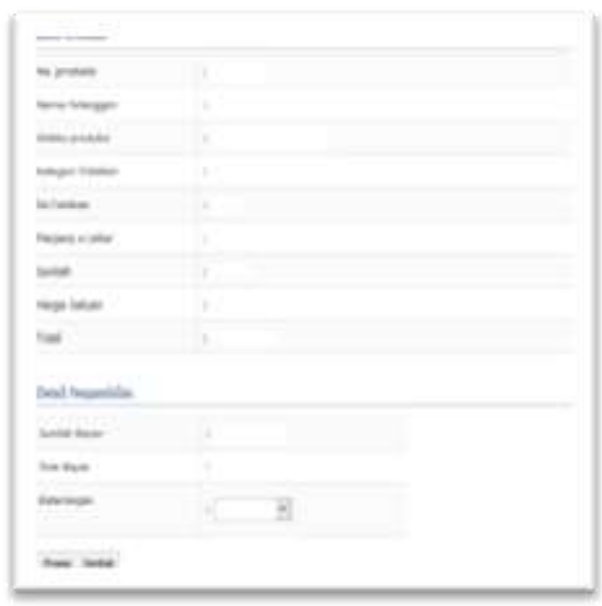

Gambar 6. Desain Data Pengambilan Order

Tampilan form Gambar 6 digunakan oleh admin untuk menampilkan data pemngambilan order, data yang diinput adalah keterangan pengambilan.

\section{Desain Input dengan Android}

a. Form Register Pelanggan

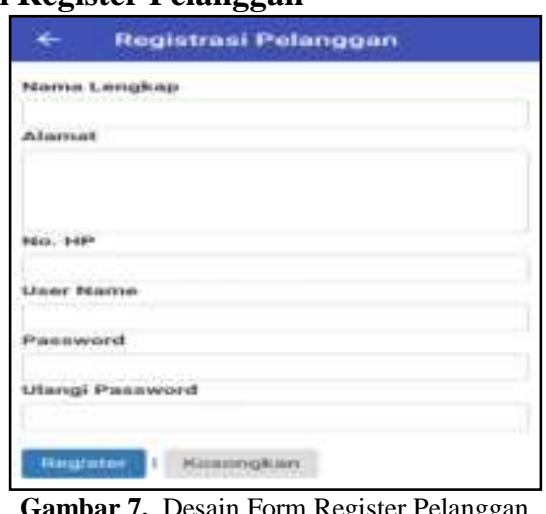

Tampilan form Gambar 7 digunakan oleh User dari pengguna android untuk melakukan register pelanggan.

\section{b. Proses Order Percetakan}

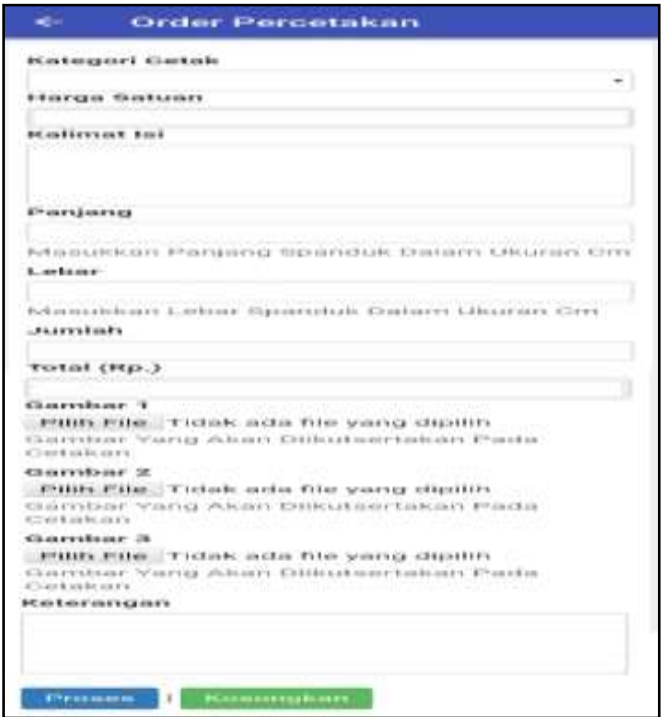

Gambar 8. Desain Proses Order Percetakan 
Tampilan form Gambar 8 digunakan oleh User dari pengguna android untuk melakukan order percetakan.

\section{Desain Sistem Secara Terinci}

Desain input secara terinci terbagi atas 2 (dua) yaitu dari sisi web dan dari sisi android. Berikut ini adalah desain input secara terinci sebagai berikut :

\section{Tampilan dari Sisi Web}

a. Desain Tampilan Login User

Tampilan halaman login user diatur seperti tampilan Gambar 1. Halaman ini akan digunakan admin untuk login ke sistem.

b. Desain Tampilan Input Data Kategori Cetak

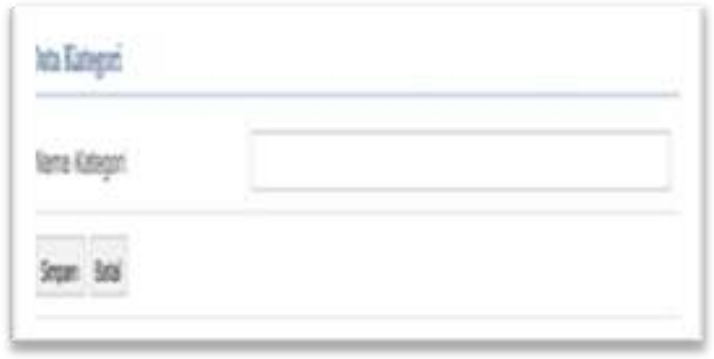

Gambar 9. Tampilan Input Data Kategori Cetak

Tampilan halaman input data kategori cetak diatur seperti tampilan Gambar 9. Halaman ini akan digunakan admin untuk input data kategori cetak.

\section{c. Desain Tampilan Input Data Setting Harga}

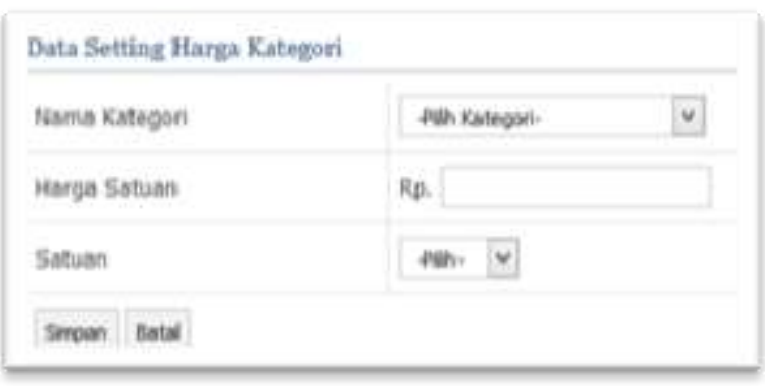

Gambar 10. Tampilan Input Data Setting Harga

Tampilan halaman input data setting harga diatur seperti tampilan Gambar 10. Halaman ini akan digunakan admin untuk input data setting harga.

\section{d. Desain Tampilan Data Order}

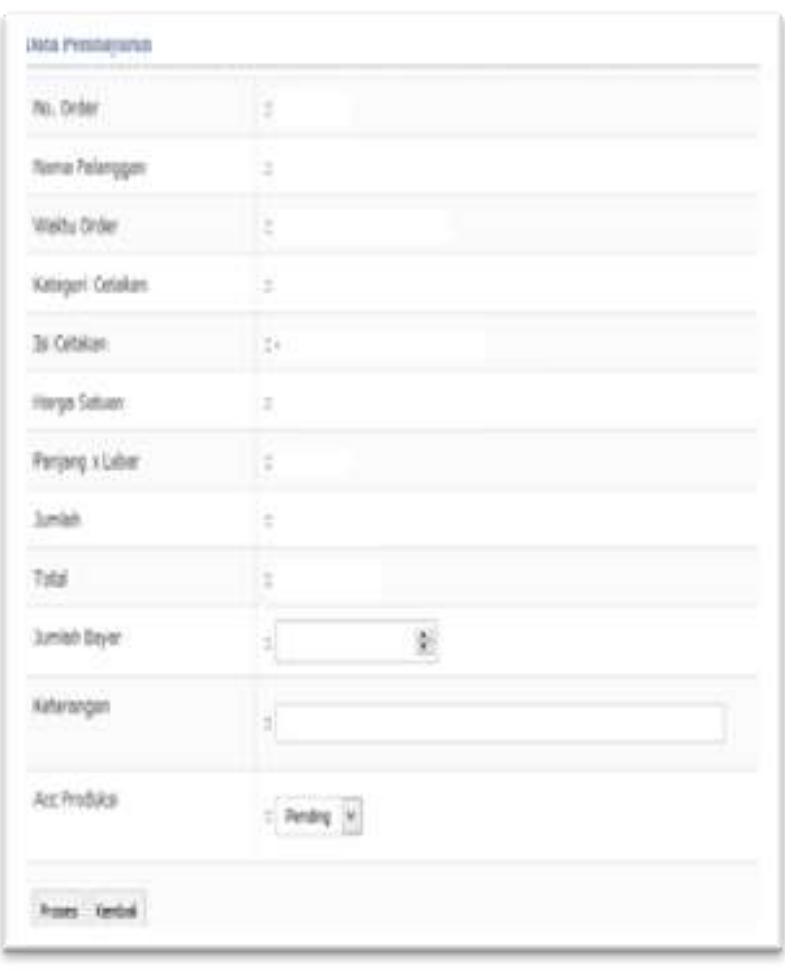

Gambar 11. Tampilan Input Data Order

Tampilan halaman tampil data order percetakan diatur seperti tampilan Gambar 11. Halaman ini akan digunakan admin untuk proses order percetakan.

\section{e. Desain Tampilan Data Produksi}

\begin{tabular}{|c|c|c|}
\hline \multicolumn{3}{|l|}{ Data Prodaksi } \\
\hline No. produksi & : & \\
\hline Namb Pelanggan & $:$ & \\
\hline Waltu produks & : & \\
\hline Kategur Cetakan & : & \\
\hline Is Cetaban & $:$ & \\
\hline Panjangx Lebar & : & \\
\hline Jumblah & : & \\
\hline Keterangan Produlsi & & $v$ \\
\hline Proser Kenbs & & \\
\hline
\end{tabular}

Gambar 12. Tampilan Input Data Produksi

Halaman tampil data produksi percetakan diatur seperti tampilan Gambar 12. Halaman ini akan digunakan admin untuk proses produksi percetakan. 


\section{f. Desain Tampilan Data Pengambilan Order}

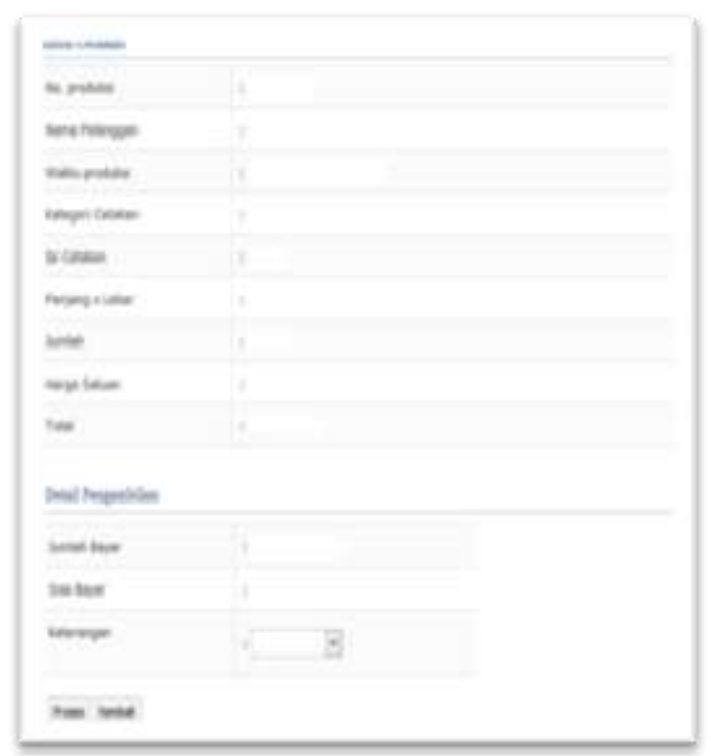

Gambar 1C3. Tampilan Input Data Pengambilan Order

Halaman tampil data Pengambilan Order percetakan diatur seperti tampilan Gambar 13. Halaman ini akan digunakan admin untuk proses Pengambilan Order percetakan.

\section{Tampilan dari sisi Android}

a. Desain halaman splash dan login konsumen

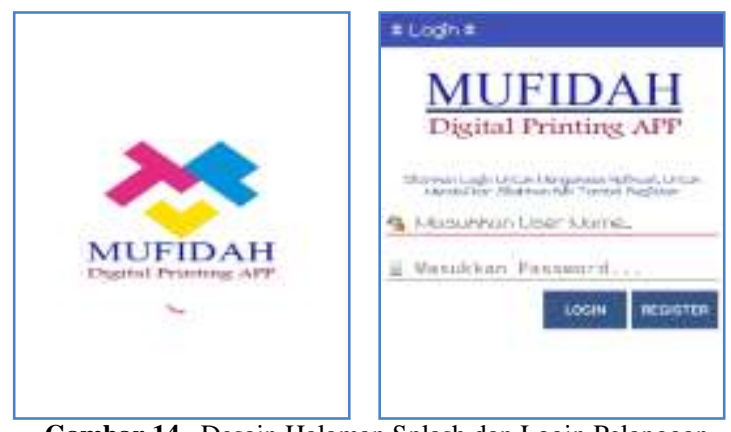

Gambar 14. Desain Halaman Splash dan Login Pelanggan

Tampilan halaman splash dan login konsumen diatur seperti tampilan Gambar 14. Halaman ini akan tampil ketika aplikasi di akses pertama kali.

\section{b. Desain halaman register Pelanggan}
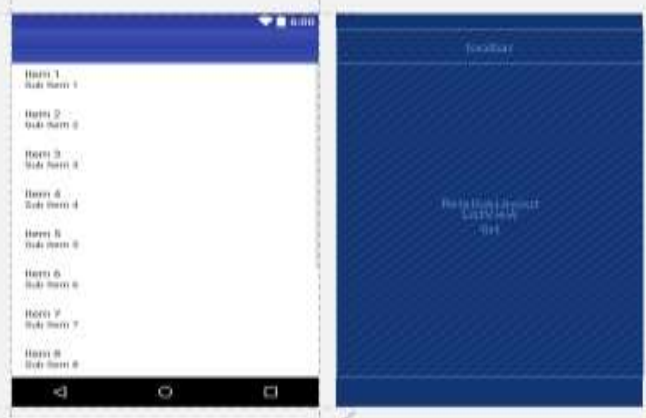

Gambar 15. Desain Halaman Register Pelanggan
Tampilan halaman register pelanggan diatur seperti tampilan Gambar 15. Halaman ini akan digunakan user pelanggan untuk melakukan registrasi user pelanggan.

\section{c. Desain halaman Order}

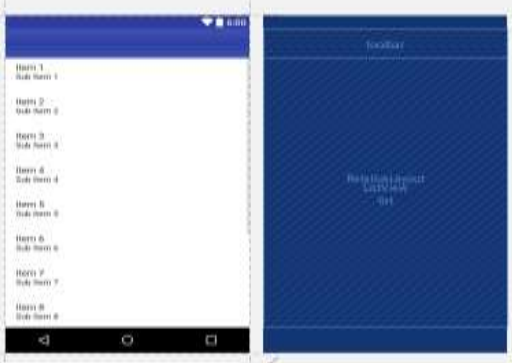

Gambar 16. Desain Halaman Order

Tampilan halaman order diatur seperti tampilan Gambar 16. Halaman ini akan digunakan user untuk melakukan order percetakan.

\section{Desain Layout Menu}

Desain layout menu dari sisi web dperlihatkan pada Gambar 17 dan desain dari sisi android diperlihatkan pada Gambar 18.

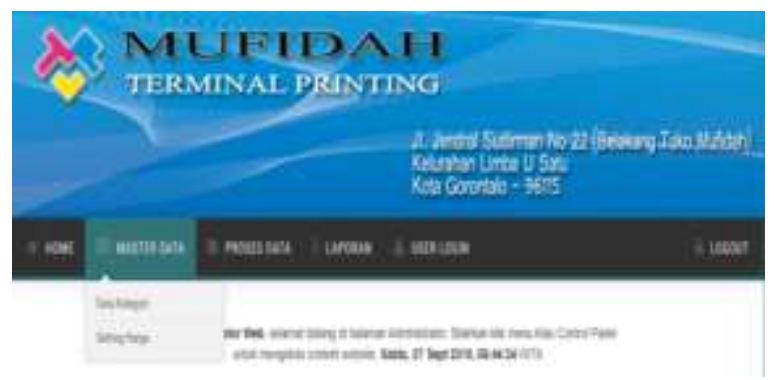

Gambar C 17. Desain Menu Sisi Web
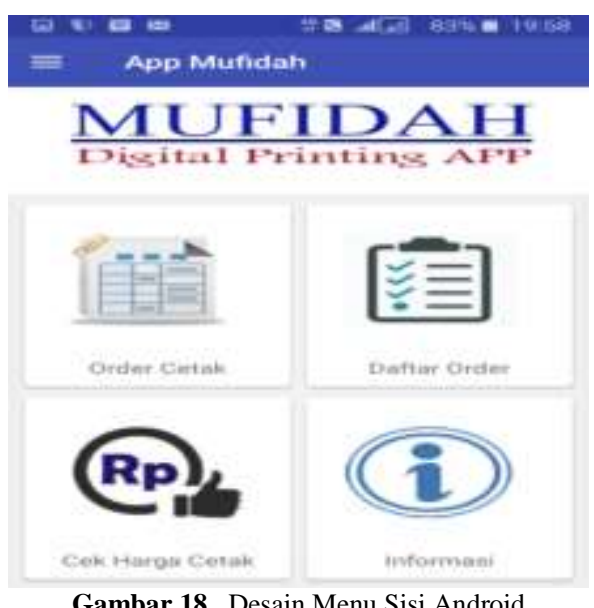

Gambar 18. Desain Menu Sisi Android

\section{E. Pengujian Perangkat Lunak}

Pengujian sistem dilakukan untuk mengukur apakah sistem yang dikembangkan telah sesuai dan dapat berjalan dengan alur yang telah direncanakan sebelumnya.

Pengujian menggunakan teknik uji coba whitebox pada alur program struktur logika program dan prosedur program dengan cara pemetaan flowchart, kemudian menghitung besarnya jumlah edge dan node, dimana jumlah edge ini 
akan menentukan besarnya cyclomatic complexcity. Pada perhitungan cyclomatic complexcity jika:

1. $V(G)=E-N+2$ hasilnya sama dengan $V(G)=P+1$

2. Jika flowgraph mempunyai region sama dengan jumlah $V(G)$ maka sistem sudah terbukti efektif dan efisien.

Untuk pengujian white box, artikel ini menggunakan modul order cetak yang dilakukan dari sisi client smart phone android.

\section{Flowgraph}

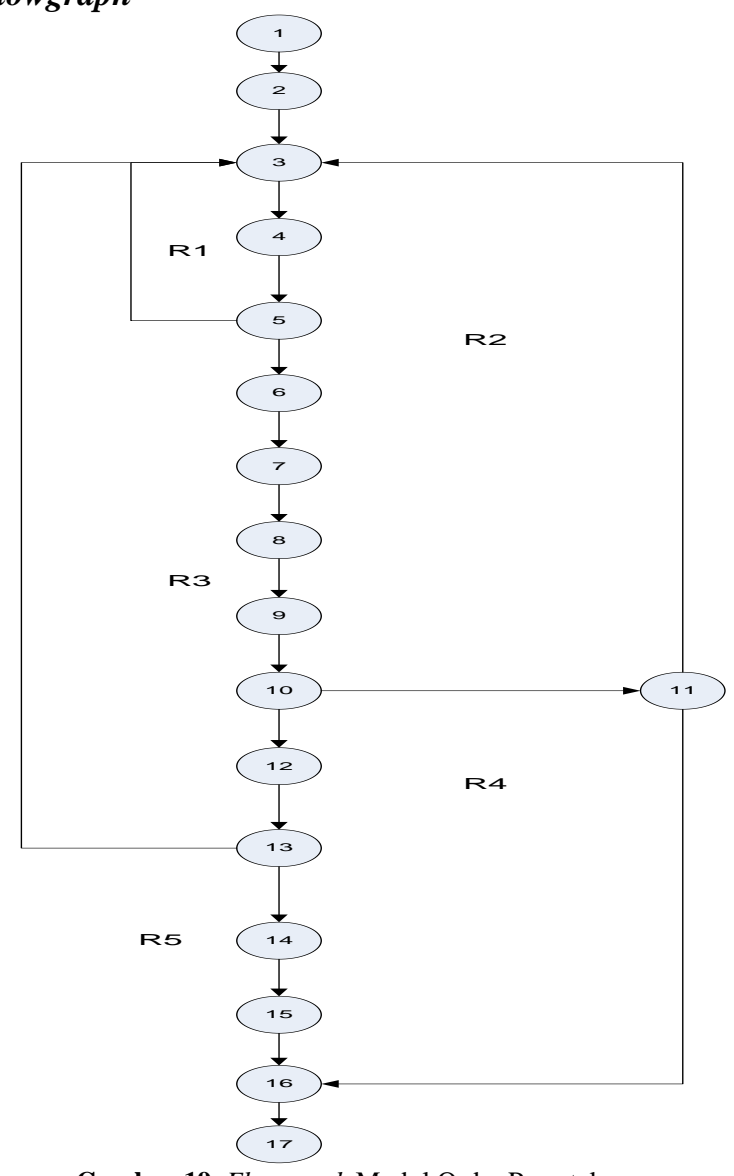

Gambar 19. Flowgraph Modul Order Percetakan

Gambar 19 adalah flowgraph dari modul order cetak yang menapilkan node dari 1 sampai node 17 . Ini adalah langkah-langkah kerja untuk melakukan order cetak di Mofida Digital Printing APP.

\section{Pseudocode}

Node 1 : Start / mulai

Node 2 : Aktifkan file kategori dan setting harga

Node 3 : Pilih kategori cetak

Node 4 : Cari kategori di file kategori

Node 5 : dapat ? jika ya lanjut ke node 6, jika tidak ke node 3

Node 6 : Tampilkan harga satuan

Node 7 : Input kalimat isi, jumlah cetak

Node 8 : Total harga

Node 9 : Ambil gambar, input keterangan

Node 10 : proses? Jika ya ke node 12 jika tidak ke node 11
Node 11 : Kosongkan?jika ya ke node 3, jika tidak ke node 16

Node 12 : Validasi data

Node 13 : valid? jika ya ke node 14 , jika tidak ke

node 3

Node 14 : Simpan Data

Node 15 : Tampilkan pesan sukses order

Node 16 : Tutup semua file

Node 17 : Finish/ selesai

\section{Perhitungan Cyclomatic Complexcity (CC)}

Dari flowgraph untuk modul order percetakan di ketahui bahwa nilai:

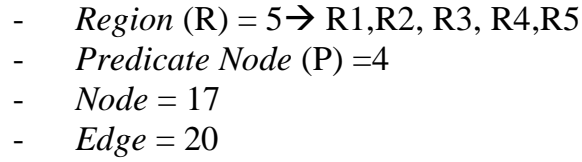

1. $\mathrm{V}(\mathrm{G})=\mathrm{E}-\mathrm{N}+2$ $=(20-17)+2=5$

2. $\mathrm{V}(\mathrm{G})=($ Predicate Node $(\mathrm{P})+1)=4+1=5$

3. Ciclometic Complexity $(\mathrm{CC})=\mathrm{R} 1, \mathrm{R} 2, \mathrm{R} 3, \mathrm{R} 4, \mathrm{R} 5=\mathbf{5}$

Perhitungan Independent Path

Independent Path untuk modul order percetakan yaitu:

$$
\begin{aligned}
& \mathrm{R} 1=1,2,3,4,5,3 \ldots \\
& \mathrm{R} 2=1,2,3,4,5,6,7,8,9,10,11,3 \ldots \\
& \mathrm{R} 3=1,2,3,4,5,6,7,8,9,10,12,13,3 \ldots \\
& \mathrm{R} 4=1,2,3,4,5,6,7,8,9,10,11,16 \ldots \\
& \mathrm{R} 5=1,2,3,4,5,6,7,8,9,10,12,13,14,15,16,17 \\
& \text { Berdasarkan hasil pengujian di atas diperoleh : } \\
& \text { - } \quad \mathrm{V}(\mathrm{G})=\mathbf{5} \\
& \text { - } \quad \text { Cyclometic Complexity }(\mathrm{CC})=\mathbf{5}
\end{aligned}
$$

Maka dapat disimpulkan bahwa alur logika untuk modul order percetakan yang dilakukan oleh user konsumen dari sisi client smartphone android adalah efektif dan efisien.

\section{F. Pembahasan \\ Implementasi Sistem}

Sistem yang dirancang selanjutnya akan diimplementasikan pada Percetakan Mufidah Digital Printing Kota Gorontalo. Untuk aplikasi sisi server akan langsung di pasang pada Percetakan Mufidah Digital Printing Kota Gorontalo dan akan dioperasikan oleh kasir, selanjutnya untuk aplikasi mobile akan diupload ke play store agar dapat diunduh secara gratis.

Untuk mengoperasikan aplikasi ini dibutuhkan smartphone dengan sistem operasi android minimum adalah kit kat. Aplikasi ini juga membutuhkan internet untuk berkomunikasi dengan ke server.

\section{KESIMPULAN}

Kesimpulan dari artikel ini yakni; sistem yang dirancang memudahkan konsumen untuk melakukan proses order cetak; sistem ini juga dapat memberikan informasi harga cetak per item produksi cetakan kepada konsumen; berdasarkan hasil perhitungan Cyclomatic Complexity (CC) dari flowgraph untuk modul order percetakan di ketahui bahwa nilai: Region $(\mathrm{R})=5 \rightarrow \mathrm{R} 1, \mathrm{R} 2, \mathrm{R} 3, \mathrm{R} 4, \mathrm{R} 5$; Predicate Node $(\mathrm{P})=4 ;$ Node $=17 ;$ Edge $=20$. Dengan 
perhitungan $\mathrm{V}(\mathrm{G})=20-17+2=5 ; \mathrm{V}(\mathrm{G})=4+1=5$; Cyclomatic Complexity $(\mathrm{CC})=\mathrm{R} 1, \mathrm{R} 2, \mathrm{R} 3, \mathrm{R} 4, \mathrm{R} 5=5$; dengan perhitungan Independent Path $\mathrm{V}(\mathrm{G})=5 ;$ Cyclomatic Complexity $(\mathrm{CC})=5$.

\section{REFFERENSI}

[1] Mufidah, "Mufidah," Gorontalo, 2018.

[2] R. Hidayat, (2016). "sistem informasi pemesanan jasa cetak berbasis web pada CV. Vida Plus Jakarta," STMIK Nusa Mandiri , Jakarta,

[3] W. Priadi and Nurgiyatna, (2014) "Perancangan Sistem Informasi Penjualan Kerajinan Rotan Berbasis Android (Studi Kasus di Klaster
Rotan Trangsan, Gatak, Sukoharjo)," Universitas Muhammadiyah, Surakarta.

[4] S. E. N., (2017). "Aplikasi Informasi Dan Pemesanan Tiket Travel Berbasis Android," Universitas PGRI Yogyakarta, Yogyakarta,.

[5] F.R. Usman, W. Ridwan, I.Z. Nasibu, Sistem Peringatan Dini of Electrical and Electronics Engineering, Vol. 1 No. 1 Januari 2019.

[6] F. Tahir, W. Ridwan, I.Z. Nasibu, Monitor Kualitas Udara Berbasis Web Menggunakan Raspberry Pi dan Modul Wemos D1, Jurnal Wek Menggunakan Raspberry

[7] Y.H. Kanoi, S. Abdussamad, S.W. Dali, Perancangan Jam Digital De Jambura Journal of Electrical and Electronics Engineering, Vol. 1 No. 2 Juli 2019. 